\title{
Choosing Targets for Gene Therapy
}

\author{
Karina J. Matissek, Ruben R. Bender, \\ James R. Davis and Carol S. Lim \\ University of Utah \\ USA
}

\section{Introduction}

Gene therapy is often attempted in fatal diseases with no known cure, or after standard therapies have failed. Targeting gene defects includes addressing a single mutation, multiple mutations in several genes, or even addressing missing or extra copies in a particular disease. A defect in one specific gene may impair normal function of the corresponding expressed protein. For example, in X-linked severe combined immunodeficiency (X-SCID), there is a mutation in the IL2 receptor $\gamma$ gene. Another classic example occurs in thalassemia propagated by a defect in the $\beta$-globulin gene. Some diseases are caused by multiple mutations in several genes. For example, some cardiovascular diseases may manifest due to mutations in different chromosomes which are a result of inherited or environmental factors. Before approaching a disease using gene therapy, the key protein(s) and pathways involved in the disease should first be identified. However, in some cases an abnormal gene is formed that results in disease; such is the case for the Bcr$\mathrm{Abl}$ gene. The oncogenic Bcr-Abl protein is the causative agent of chronic myelogenous leukemia (CML) which could be blocked for CML treatment. Genomic sequencing information, microarrays, and biochemical assays can be used to determine up- or downregulated proteins involved in disease, and will help determine the function of these proteins. In the case of some cancers, the signal transduction pathways for oncogenesis have been mapped out, allowing hub proteins to be identified. Hub proteins are essential proteins that interact with multiple other proteins in signaling cascades. If selected properly, adding back a tumor-suppressing hub protein (such as p53), or blocking an oncogenic hub protein (such as survivin) could halt cancer or alter disease progression. Gene mutations can result in mislocalization of these key proteins which can cause cancer; this mislocalization can be exploited with gene therapy approaches. Further, new types of gene therapy are being developed in our lab to direct proteins to other cellular compartments where their function is altered. This chapter will summarize these and other known targets and also focus on choosing newer targets for gene therapy.

\section{Known targets for gene therapy}

The general aim of gene therapy is to introduce a well-defined DNA sequence into specific cells. Almost any disease can be targeted with gene therapy by replacing defective genes or imparting a new function. In fact, $85 \%$ of clinical trials in gene therapy have been conducted for cancer, cardiovascular diseases and for inherited monogenic diseases. In addition, $6.5 \%$ 
of clinical trials have been conducted for infectious diseases (mainly HIV). Cancer, cardiovascular diseases and HIV are ideal gene therapy targets because of their enormous prevalence and the associated fatal consequences of these diseases, whereas monogenic disorders reflect the original idea of gene therapy which is replacement of a defective gene. Gene therapy offers a unique opportunity to cure patients with monogenic disorders. One third of clinical trials for monogenic disorders are for cystic fibrosis while about $20 \%$ are for SCID (Edelstein et al. 2004). This section highlights the advantages of gene therapy for multifactorial diseases such as cancer, vascular diseases, and HIV and describes the utility of gene therapy for monogenic diseases such as cystic fibrosis, SCID and $\beta$-thalassemia.

\subsection{Cancer}

Cancer was responsible for 7.6 million deaths in 2008 (WHO 2011) and is the largest target for gene therapy clinical trials. The complexity of cancer may make it difficult to bring a product to the market due to the number of genes involved compared to monogenetic disorders. However, gene therapeutics are not designed to correct these mutations by adding an enormous amount of DNA to the cells. Instead, they target critical proteins involved in signaling cascades such as the tumor suppressor p53. For example, the first gene therapy product was Gendicine ${ }^{\mathrm{TM}}$, an adenovirus containing the tumor suppressor $\mathrm{p} 53$.

The tumor suppressor p53 is mutated in $40 \%$ of many types of cancers, and malfunction of p53 is the major contributor for chemotherapy resistance (Goh et al. 2011). Apoptosis can be triggered by transcriptionally active p53 in the nucleus (Taha et al. 2004) as well as by p53mediated transcriptionally independent mechanisms in the mitochondria (Vaseva et al. 2009). Various animal studies have shown that p53 induces apoptosis even in advanced tumors such as lymphoma and hepatocellular carcinoma (Ventura et al. 2007; Palacios \& Moll 2006; Xue et al. 2007).

The first p53 based gene therapy in humans was conducted in 1996. This trial used a retroviral vector containing wild type p53 with an actin promoter for the treatment of nonsmall cell lung carcinoma. In this study three patients showed tumor regression and three other patients showed tumor growth stabilization (Roth et al. 1996). China was the first country which approved a p53 adenovirus for gene therapy, Gendicine ${ }^{\mathrm{TM}}$ SiBiono, in combination with radiotherapy for head and neck squamous cell cancer in 2004 (Shi \& Zheng 2009). Gendicine ${ }^{\mathrm{TM}}$ is a recombinant serotype 5 adenovirus with the E1 region replaced by the p53 expressing cassette (with a Rous sarcoma virus promoter). The adenovirus particles infect tumor target cells carrying therapeutic p53 (Peng 2005). Clinical trials for Gendicine ${ }^{\mathrm{TM}}$ showed that in combination with radiation therapy it caused partial or complete tumor regression (Peng 2005; Xin 2006). There were also some clinical trials for Gendicine ${ }^{\mathrm{TM}}$ in advanced liver cancer, lung cancer and other advanced solid tumors (Peng 2005). It should be kept in mind that China's State Food and Drug Administration (SFDA) has different standards for the approval of a cancer drug compared to the U.S. FDA and the European Medicine Agency (EMA). Gendicine ${ }^{\mathrm{TM}}$ was approved in China on the basis of tumor shrinkage. The U.S. FDA and the EMA require novel cancer drugs to extend the lifetime of the treated patients (Guo \& Xin 2006).

Another p53 product is Oncorine ${ }^{\mathrm{TM}}$ from Shanghai SunwayBiotech, an oncolytic virus. Oncorine ${ }^{\mathrm{TM}}$ was approved for the treatment of head and neck cancer in China in 2006 (Yu \& Fang 2007). It is a replicative adenovirus 2/adenovirus 5 hybrid with deletion in E1B55K and E3B (Raty et al. 2008). This oncolytic virus was expected to infect and lyse cancer cells only and not affect normal cells (Guo et al. 2008). Even though clinical studies showed that it 
was not specific for cancer cells, it did, however, kill tumor cells preferentially (Garber 2006). Phase I/II trials showed little dose-limiting toxicity (Lockley et al. 2006) and the combination of Oncorine ${ }^{\mathrm{TM}}$ with chemotherapy showed greater tumor shrinkage in patients with head and neck cancer, compared to chemotherapy alone. It should be kept in mind that like Gendicine ${ }^{\mathrm{TM}}$, Oncorine ${ }^{\mathrm{TM}}$ was also approved by the SFDA based on objective response rate, not on survival (Garber 2006). Nevertheless, all the available data concerning p53 and its proven function as tumor suppressor qualifies it as an adjuvant treatment with radiotherapy or chemotherapy.

Another approach to cancer gene therapy is gene-directed enzyme prodrug therapy (GDEPT). GDEPT transfers an activating transgene into tumor cells followed by systemic treatment with a non-toxic drug which becomes activated only in cells expressing the transgene. CereproR is an adenovirus containing a herpes simplex type- 1 thymidine kinase transgene under the cytomegalovirus promoter. Cerepro ${ }^{\mathrm{R}}$ is under phase I, II and III clinical trials in Europe for malignant glioma, a fatal form of brain cancer. In these clinical trials Cerepro $^{R}$ was injected multiple times into healthy brain tissues of patients following surgical removal of the solid tumor mass. Then the patients were treated with the prodrug ganciclovir, which is converted to its toxic form, deoxyguanosine, by thymidine kinase. This toxic metabolite affects newly dividing cells, thus it prevents new tumors from growing. In phase I and II trials, patients given Cerepro $^{R}$ showed a significant increase in survival. However, after phase III studies, the EMA rejected the marketing application for CereproR due to inadequate efficacy (van Putten et al. 2010; Cerepro 2009; Mitchell 2010; Raty et al. 2008). Despite this particular failure, systemic side effects are avoided with the GDEPT concept. The general goal of GDEPT is the improvement of chemotherapy in terms of safety and efficiency using concomitant gene therapy (Edelstein et al. 2004).

\subsection{Cardiovascular diseases}

Cardiovascular diseases (CVD) encompass disorders of the heart and blood vessels and include hypertension, coronary heart disease, cerebrovascular disease, peripheral vascular disease, heart failure, rheumatic heart disease, congenital heart disease and cardiomyopathies (Chiuve et al. 2006). Cardiovascular diseases are the largest health problem worldwide, claiming 17.1 million lives per year. Despite the complexity of cardiovascular disease, there is great potential for gene therapy especially in ischemia, angiogenesis, hypertension and hypercholesterolemia. Currently there is no gene therapy product on the market for CVD. Nevertheless, several clinical trials have been conducted (Edelstein et al. 2004; Edelstein et al. 2007). Most gene therapies for CVD aim to increase angiogenesis which is a mechanism to overcome ischemia. Ischemia is a condition in which the flow of blood is restricted to parts of the body. The response of the body is to form new blood vessels around the blockage, called angiogenesis, and is triggered by angiogenic proteins such as vascular endothelial growth factor (VEGF), fibroblast growth factor (FGF) and hepatocyte growth factor (HGF) (Abo-Auda \& Benza 2003; Kass et al. 1992). The goal of introducing genes coding for these growth factors is to increase the local concentration of these factors to stimulate angiogenesis (Edelstein et al. 2004). Two companies are conducting phase III clinical trials using FGF. Bayer Schering Pharm AG has developed alferminogene tadenovec, which is a replication-deficient human adenovirus serotype 5 which encodes human FGF4. Since myocardial ischemia is linked to coronary artery disease, the therapeutic goal is to improve the reperfusion of ischemic myocardium. Phase IIb/III clinical trials showed that it is well-tolerated; a phase III trial is ongoing to prove its efficacy (Flynn \& 
O'Brien 2008; CardioVascular BioTherapeutics). Sanofi-Aventis is developing a FGF gene therapy product called riferminogene pecaplasmide or NV1FGF (Riferminogene pecaplasmide 2010). It is a novel pCOR (conditional origin of replication) plasmid-based gene delivery system (Maulik 2009). NV1FGF is injected into muscle cells, and expresses FGF-1. The therapeutic goal is to treat chronic/critical limb ischemia since limb ischemia is linked to peripheral artery disease (Baumgartner et al. 2009). Phase III clinical trials are ongoing in 32 countries (Riferminogene pecaplasmide 2010).

Another gene therapy approach to treat limb ischemia uses HGF. There are several animal studies showing that HGF can trigger formation of new blood vessels (Shigematsu et al. 2010). The injection of the naked HGF gene is well-tolerated as shown in the first clinical trial conducted in Japan (Morishita et al. 2004). Another clinical trial in the U.S. showed that HGF injection increased tissue perfusion compared to placebo (Powell et al. 2008). Lastly, there is also a clinical trial to prove efficacy of HGF gene therapy, using reduction of ulcer size and decrease in rest pain (pain occurring during sleep) as objectives (Shigematsu et al. 2010).

\subsection{HIV}

The human immunodeficiency virus (HIV) causes acquired immunodeficiency syndrome (AIDS), a severe disease characterized by profound negative effects on the immune system leading to life-threatening opportunistic infections. Although antiretroviral drugs have decreased the morbidity and mortality of HIV infected patients, currently there is no cure. However, new developments in gene therapy have focused on introducing genes encoding RNA or proteins which are capable of interfering with intracellular replication of HIV, socalled intracellular immunization. So far, the approaches range from protein-based strategies such as fusion inhibitors or zinc finger nucleases to RNA-based approaches such as ribozymes, antisense or short hairpin RNA. Currently, a promising target is the chemokine receptor 5 (CCR5) which is needed for fusion of HIV with immune cells. Studies have shown that patients with mutated CCR5 have a higher long-term survival and slower progression of the disease. A homozygous defect in the CCR5 gene, a $\Delta 32$ deletion, resulting in a lack of functional CCR5 protein and confers resistance to HIV infection (Liu et al. 1996). An allogeneic stem-cell transplantation of CCR5 defective cells in a patient with HIV infection and acute myeloid leukemia resulted in both a negative HIV plasma viral load and no detection of HIV proviral DNA for more than 3.5 years after treatment (without the use of antiviral drugs). This result has been classified as a cure of HIV (Kitchen et al. 2011, and references therein; Symonds et al. 2010, and references therein).

\subsection{Monogenic diseases}

Monogenic diseases are prime targets for gene therapy due to their simple single gene mutations. Their disease causing mechanisms are easier to elucidate which is advantageous for choosing a target for gene therapy. In addition, the execution of therapy is more straightforward, since it is easier to transfer single genes into cells instead of several genes. Other important factors are the location and the type of cell in which the gene has to be transferred. Is the cell reachable with existing delivery systems? Is the cell already differentiated or is it a still dividing stem cell? Does gene transfer need to be repeated or is a one-time transfer sufficient? All these questions have to be considered in order to choose the right target for gene therapy, and it must be noted that not every disease caused by single gene mutations can be targeted. Three examples of well-studied diseases and attempts to treat these diseases using gene therapy will be discussed. 


\subsubsection{Cystic fibrosis}

Cystic fibrosis (CF) is a complex inherited disease affecting the lungs and digestive system. The cause of this disease is a defect in the cystic fibrosis transmembrane conductance regulator (CFTR), which is a chloride channel on the apical membrane of respiratory epithelia. This leads to reduced $\mathrm{Cl}^{-}$and increased $\mathrm{Na}^{+}$permeability (Boucher et al. 1988). CF is caused by several different mutations in the CFTR gene located on chromosome 7 (Knowlton et al. 1985). Of the hundreds of mutations that cause CF, the most common mutation, which occurs in approximately $70 \%$ of all cases, is the deletion of a phenylalanine residue at amino acid position $508(\Delta \mathrm{F} 508)$ (Kerem et al. 1989). CF results in decreased production of pancreatic enzymes leading to malnutrition, and also blocks the lung with unusually viscous mucus leading to life-threatening infections (Cystic Fibrosis Foundation; Wood 1997). It is possible to treat symptoms of CF to improve quality of life but there is no current cure for this disease. Mainstays for symptomatic treatment include enzymatic therapies (pancreatic enzymes and DNAse I) (McPhail et al. 2008), airway clearance and hypertonic saline for improved lung function, use of drugs that enhance $\mathrm{Cl}^{-}$secretion in airway epithelium (Cloutier et al. 1990) and anti-inflammatories involving ibuprofen or corticosteroids (Flume et al. 2010, and references therein). Despite a clear understanding of genetic links, gene therapy is not yet a standard treatment for $\mathrm{CF}$, as recent attempts to cure patients with $\mathrm{CF}$ have not been successful. Moss et al. showed improvement in pulmonary function in a phase II clinical trial with 42 CF patients, of whom 20 received at least one dose of aerosolized adeno-associated serotype 2 virus carrying the CFTR gene. A significant enhancement in $\mathrm{FEV}_{1}$ (forced expiratory volume per second) was noted after 30 days compared to placebo. Furthermore, this study showed no adverse events demonstrating the safety of adeno-associated vectors (Moss et al. 2004). However, when this same group performed a second, larger phase IIb trial with 102 subjects, there was no significant improvement in FEV1 seen after 30 days compared with placebo (Moss et al. 2007). Expression of CFTR was noted in airway epithelium of 7 individuals with CF after the first administration but the effect lasted only 30 days. The second administration showed decreased expression. Finally, at the third administration, the expression fell to zero (Harvey et al. 1999). In conclusion, there is some indication that gene therapy could be used to cure $\mathrm{CF}$, but no method has shown to be universally applicable. Further research is needed to find the right vector with repeatable administration and subsequent high expression while simultaneously being safe. Gene therapy for $\mathrm{CF}$ targets epithelial cells which have a limited life span and do not divide. Because of that, the gene has to be transferred repeatedly into new growing cells, which is problematic since repeated transfections have been ineffective.

\subsubsection{Severe combined immunodeficiency}

Severe combined immunodeficiency (SCID) is a rare, fatal syndrome with an incidence of 24.3 cases per million live births (Ryser et al. 1988). The disease is characterized clinically by defects in humoral and cellular immunity due to profound deficiencies of T-and B-cell function, and if left untreated usually leads to death in infancy (Buckley et al. 1997). Mutations leading to SCID appear in various genes including Jak-3, adenosine deaminase, IL-7 receptor (Puel et al. 1998), tyrosine phosphatase CD45 (Kung et al. 2000), the interleukin-2 (IL-2) receptor $\gamma$ chain (IL2-RY), the Artemis gene (Kobayashi et al. 2003) and recombinase activating genes 1 or 2 (Schwarz et al. 1996; Buckley et al. 1997, and references therein). The most frequently diagnosed form of SCID is X-SCID, which is characterized by a mutation in the IL2-RY gene located on the $X$ chromosome. This disease shows a male 
predominance, with a mean age of diagnosis of 6.6 months. The IL2-RY chain is a critical component of many cytokine receptors including those for IL-2, -4, -7, -9, -15 and 21, where defects may result in greatly decreased numbers of T and NK cells. The number of B cells is generally normal but their activity is abnormal (Buckley et al. 1997). After maternal antibodies have vanished, the extreme susceptibility to infection due to opportunistic microbes, persistent diarrhea and failure to thrive usually lead to death in the first year of life unless immunologic reconstruction can be achieved.

Hematopoietic stem cell transplantation is the standard of care for all genetic types of SCID with a survival rate of nearly $80 \%$ with HLA-identical parental marrow (Antoine et al. 2003). Even with a matched donor, stem cell transplantation may lead to long-term clinical complications (De Ravin \& Malech 2009). Thus, other treatments for SCID are needed. An ex vivo gene therapy trial with two X-SCID patients, aged 8 and 11 months, demonstrated that gene therapy has curative potential. Administration of a retroviral vector containing the correct IL2-RY gene resulted in T cell counts similar to that of age-matched controls after 105 days. Furthermore, the immune system responded to tetanus toxin and polioviruses within the normal range after primary vaccination. Both patients later showed normal growth and psychomotor development (Cavazzana-Calvo et al. 2000). Other studies confirmed these results (Hacein-Bey-Abina et al. 2002; Thrasher et al. 2005). A separate study of gene therapy for X-SCID with children aged 2.5, 4 and 8 years old showed mixed results. Only the youngest patient experienced benefit from the treatment (Chinen et al. 2007). Another trial with two patients, aged 15 and 20 years old also failed (Thrasher et al. 2005). Despite the variable outcome from these studies, gene therapy may still potentially cure X-SCID and other SCIDs, in particular for younger patients. It is already possible to cure newborn children with this modern technique, if traditional methods like BMT fail. If the safety of gene therapy vectors can be improved to lower the risk of insertional mutagenesis, gene therapy will likely become first-line therapy for to the treatment of X-SCID. In contrast to $\mathrm{CF}$, the presence of accessible stem cells in which the functional gene could be transferred would allow continuous expression of this gene, making X-SCID a good candidate for gene therapy.

\subsection{3 $\beta$-thalassemia}

$\beta$-thalassemia syndromes are a group of inherited blood disorders. Thalassemia major is the only transfusion-dependent type of $\beta$-thalassemia and manifests itself clinically between 6 and 24 months of life by paleness and failure to thrive. It is marked by reduced $\left(\beta^{+}\right)$or absent $\left(\beta^{0}\right)$ beta globin chain synthesis caused by several different single gene mutations, resulting in reduced hemoglobin in red blood cells (Weatherall 1976). If left untreated, this disease results in growth retardation, pallor, jaundice, poorly developed musculature, skeletal changes and other consequences leading to death during infancy (Cao \& Galanello 2010). Blood transfusion is the current standard therapy for $\beta$ thalassamia and aims to correct the anemia from reduced hemoglobin (Cao \& Galanello 2010). This treatment, however, carries the risk of infection from blood borne diseases such as HIV and hepatitis and as well as the serious side effect of transfusional iron overload which is fatal if untreated. Currently, BMT offers the best chance for curing $\beta$ thalassemia in both in children and adults if a HLA identical donor is found, but is limited by complications like graft-versus-host disease or finding suitable donors (Lucarelli \& Gaziev 2008). 
Gene therapy of human $\beta$-thalassemia is still in its infancy and requires the development of efficient, safe and high level gene transfer into target hematopoietic stem cells. It also requires regulation of erythroid lineage-specific expression and therapeutic levels of $\beta$ globin expression (Malik \& Arumugam 2005). Meeting these requirements may be difficult, but a successful gene therapy trial was achieved in 2007 when an 18 year-old patient was effectively treated using a $\beta$-globin-expressing lentiviral vector. The vector was transfected ex vivo into harvested $\mathrm{CD} 34^{+}$cells and then transplanted back into the patient's bone marrow. The patient, who had no HLA-matched donors (making BMT impossible), was treated with high dose chemotherapy with intravenous busulfan to eliminate defective hematopoetic stem cells (HSC) prior to transplantation. This step was critical for the success of this treatment to prevent the defective HSC from diluting the corrected HSC. Three years post-transplant this patient no longer required blood transfusions and showed stable hemoglobin levels. However, mild anemia, compensatory expansion of red-blood-cell precursors in bone marrow, and other safety concerns have been raised (including development of cancers) (Cavazzana-Calvo et al. 2010). Although the long-term prognosis and outcome of gene therapy for $\beta$-thalassemia is currently unclear, it still has the same advantage of the presence of accessible stem cells as X-SCID. With this in mind, targeting stem cells may be more successful than differentiated cells, and may be sufficient to cure the disease.

\section{Identifying novel targets for gene therapy}

Before targeting a disease with gene therapy, the genetic basis of that disease should be identified. Strategies for finding disease genes have greatly improved in the last few years due to the Human Genome Project and the Hap Map Project. The Hap Map Project identifies and catalogs genetic similarities and differences in humans (Human Genome Project; The International Hap Map Consortium 2003) and supplies computerized databases to search through and identify new gene therapy targets (Hap Map Project 2003). To find genes the two most common options are candidate-gene studies and genome-wide studies. Candidate-gene association studies are based on prior biological knowledge of gene function or on significant findings in linkage studies. This method is based on a single polymorphism and haplotypes and compares allele or haplotype frequencies between the case and the control group. Genome-wide studies can be divided into linkage mapping and genome-wide association studies. Genetic linkage mapping studies are used to discover and identify new genes by using genetic and phenotypic data from families. The analysis is conducted without any prior knowledge about genetic basis of disease. Linkage analysis functions by comparing genotype polymorphic markers at known locations in the genome. Genome-wide association studies are the most recent technology. They search the whole genome for single nucleotide polymorphisms (SNPs). Each study can look at hundreds or thousands of SNPs at the same time (for an excellent review see (Hirschhorn \& Daly 2005)). The results are plotted into biostatistics algorithms (Nakamura 2009; Hirschhorn \& Daly 2005). The proteins identified by genomic methods can be further characterized by standard molecular and biochemical assays. In addition, protein targets have been identified by individual labs using standard molecular and biochemical methods without a priori use of genomic information. With the growing understanding of genes associated with many diseases the future for new gene therapeutics shows promise. 


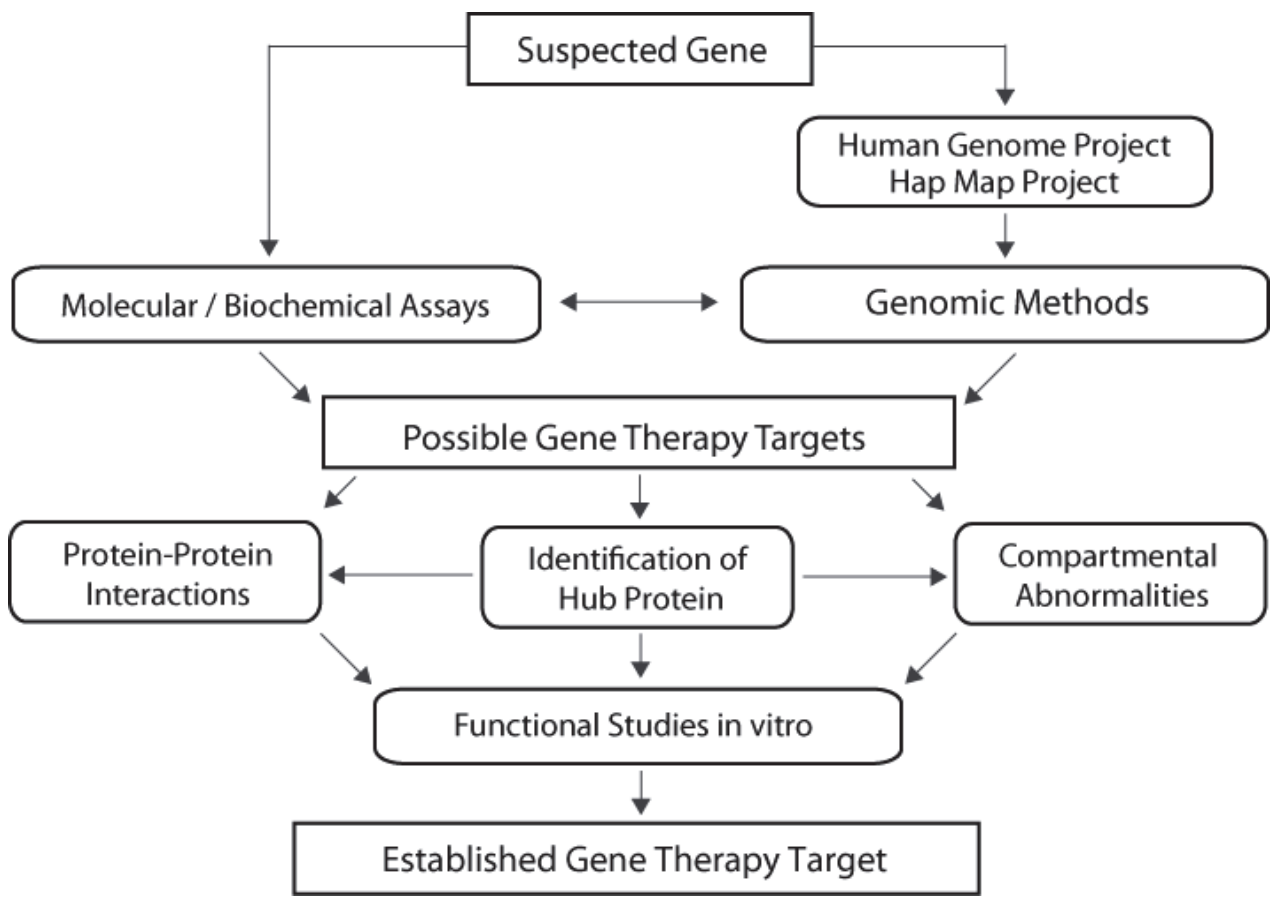

Fig. 1. Finding Novel Gene Therapy Targets. Integration of standard and modern technologies for disease-causing targets for gene therapy.

\subsection{Methods to find gene therapy targets}

Microarrays lay the groundwork for the methods mentioned above. The two most important advantages of microarrays are their small scale (multi-well plate formats) and ability to detect thousands of different immobilized genes simultaneously (Duggan et al. 1999; Siegmund et al. 2003; NCBI 2007). There are three types of microarray technologies: comparative genomic hybridization, expression analysis and mutation/polymorphism analysis, though the principle remains the same for all. First, the DNA chip corresponding to the DNA of interest is selected. Then, isolated messenger RNA (mRNA) is used as a template to generate complementary DNA (cDNA), with a fluorescent tag. This mixture is incubated with the DNA chip. During this incubation, tagged cDNA can specifically bind to the complementary DNA template on the chip. Afterwards, the hybridized cDNA can be detected with lasers specific to different fluorophores followed by analysis using computational methods (NCBI 2007).

The Human Genome Project and the HapMap project have provided the foundation for candidate gene and genome-wide studies. Using these methods may allow us to draw conclusions between gene abnormalities and diseases. For example, many different studies have been conducted to determine the genes associated with cardiovascular diseases. In fact many CVDs are linked to mutated genes. For example, there is evidence based on genetic linkage analysis that chromosomes $1,2,3,13,14,16$ and $X$ are involved in myocardial infarction, which is the major killer world-wide. Additionally, myocardial infarction and 
stroke are associated with mutations in chromosome 13q12-13 containing the ALOX5AP gene encoding arachidonate 5-lipoxygenase-activating protein. Furthermore, high LDL, low HDL and high triglycerides values are high risk factors for cardiovascular disease, with linkage results located in all autosomes except for 2 and 14 (Arnett et al. 2007, and references therein).

Finding disease-causing genes may not only help to better understand the pathophysiology of the disease, but may improve the diagnosis of the disease by discovery of disease-specific marker genes. Importantly, identification of disease-causing genes will lead to new targets for improved therapeutics. Genome-wide association studies which scan markers across the entire genome can find single mutations causing monogenic disorders as well as different mutations in several genes, which may lead to more gene therapy-based cures for these diseases.

\subsection{Hub proteins}

Genomic sequencing information, microarrays, and molecular/biochemical assays are tools that can help determine which proteins are responsible for disease. This information can be analyzed to identify hub proteins involved in disease progression. Hub proteins are key proteins that signal to multiple other proteins in transduction cascades. They are highly connected to other proteins with multiple interaction partners. Hub proteins bind with several distinct binding sites to other proteins. Studying the binding interface of cancerrelated proteins maybe useful for better understanding of cellular function and biological processes (Keskin \& Nussinov 2007; Kim et al. 2006).

\subsubsection{Tumor suppressor hub proteins}

\subsubsection{1 p53}

The tumor suppressor p53 is an example of a hub protein involved in cancer which loses the ability to bind different other proteins due to mutations (Shiraishi et al. 2004). It induces transactivation of target genes which are responsible for cell cycle arrest, DNA repair and apoptosis. p53 is mutated in $40 \%$ of cancers (Goh et al. 2010). In normal, healthy cells p53 is rapidly degraded via the MDM2 pathway, but when stress signals occur, p53 accumulates dramatically in the cell, allowing it to accomplish its apoptotic functions. p53 stimulates multiple signaling mechanisms which lead to apoptosis: the extrinsic pathway through death receptors and the intrinsic pathway through the mitochondria (Haupt et al. 2003). As a transcription factor it binds to p53-responsive genes, and the expressed proteins trigger apoptosis, G1 arrest, as well as DNA repair through different mechanisms. In addition, p53 translocates to the mitochondria and induces a rapid apoptotic response (Erster et al. 2004; Haupt et al. 2003). Consequently, p53 fulfills the requirements for an ideal hub protein for gene therapy. Indeed, p53 adenovirus has been used for cancer therapy, and was the first gene therapeutic on the market.

\subsubsection{BRCA1 and BRCA2}

Breast cancer susceptibility protein (BRCA)1 and BRCA2 are highly associated with breast and ovarian cancer. The lifetime risk of developing breast cancer for a person carrying mutations in both genes is $82 \%$; mutations in BRCA1 account for $52 \%$ and BRCA2 for $23 \%$ of all cases. Furthermore, the risk for ovarian cancer is dramatically increased due to mutations in BRCA1 and/or BRCA2. Thus, it is important to identify patients with a probability of 
having mutations in these proteins. BRCA1 and BRCA2 regulate cell cycle progression, DNA repair and gene transcription (Metcalfe et al. 2005). Their export into the cytoplasm is associated with apoptosis. In cooperation with cellular partner BARD1 (BRCA1-associated RING domain protein), BRCA1 is able to enter the nucleus and accomplish its role in DNA repair, centrosome regulation and RNA processing (Henderson 2005; Rodriguez et al. 2004). When the sensitive balance between BARD1 and BRCA1 is defective due to cancerpromoting mutations in both, they remain as a dimer which results in nuclear compartmentalization leading to dramatic reduction of their apoptotic activity (Davis et al. 2007; Rodriguez et al. 2004). Silencing BRCA1 expression using RNA-mediated interference, results in increased cytoplasmic levels of BARD1 and causes apoptosis in breast cancer cell lines (Rodriguez et al. 2004). BARD1 translocates to the mitochondria and causes oligomerization of Bax which results in apoptosis (Tembe \& Henderson 2007). Therefore, targeting BRCA1 is a viable gene therapy-based approach.

\subsubsection{Hub proteins that promote cancer}

\subsubsection{Survivin}

In addition to adding back hub tumor suppressors for gene therapy, oncogenic hub proteins can be blocked as well. The oncogene survivin is nearly universally expressed in various types of cancer and is almost undetectable in most adult tissue. Survivin is a unique member of the inhibitor of apoptosis protein (IAP) family and plays a major role as a mitotic regulator (Altieri 2001, and references therein). It is involved in multiple cancer-promoting mechanisms, particularly inhibition of apoptosis. Various parallel pathways, such as intervention in mitochondrial function, inhibition of caspases, and influence on gene expression are responsible for survivin's anti-apoptotic function (Altieri 2008, and references therein). For example, survivin and its binding partners act to prevent caspase activation; activated caspase 9 is required to activate effector caspase 3 and caspase 7, which execute mitochondrial-induced apoptosis (Li \& Yuan 2008). Also, a splice variant of survivin, survivin $\Delta \mathrm{Ex}-3$, translocates to the mitochondria where it interacts with proteins from the Bcl-2 family. These proteins are inhibitors of permeabilization of the mitochondrial outer membrane which is essential for cytochrome c release. Stabilization of Bcl-2 proteins prevents cytochrome c release, thus resulting in the inhibition of caspase 9 and caspase 3 (Altieri 2008, and references therein). Furthermore, survivin's role as a mitotic regulator is related to its inhibition of apoptosis. Survivin expression is upregulated at the G2/M phase to localize to the mitotic apparatus and is downregulated in interphase via ubiquitindependent destruction ( $\mathrm{Li}$, Ambrosini, et al. 1998; Zhao et al. 2000). High survivin expression was detected in various types of cancers including breast, lung, colon, stomach, esophagus, pancreas, uterus, ovary and liver (Altieri 2008, and references therein). Dramatic overexpression of survivin correlates with more aggressive and invasive clinical phenotypes which means a poor prognosis compared to survivin-negative tumors, an increased rate of recurrence and chemotherapy resistance (Kato et al. 2001; Grossman \& Altieri 2001). The differential expression and function of survivin make it an excellent target for cancer therapy (Altieri 2003). There are many gene-based strategies to inhibit survivin in cancer cells, with some in phase I and II clinical trials. One gene-based method uses survivin antisense oligonucleotides to prevent expression in cancer cells. Two phase II trials and one phase I trial by Eli Lilly and Co. are ongoing for relapsed or refractory acute myeloid leukemia, hormone refractory prostate cancer and advanced hepatocellular carcinoma (Ryan 
et al. 2009). Furthermore, Alteri et al. created a replication-deficient adenovirus containing a dominant negative survivin mutant where threonine 34 is mutated to alanine. This mutation abrogates phosphorylation of threonine which impairs survivin's ability act as a mitotic regulator, as only phosphorylated survivin is able to localize to the mitotic apparatus (O'Connor et al. 2000). Injection of adenovirus containing survivin mutant triggers apoptosis by cytochrome c release which leads to caspase 3 activation. Alteri et al. demonstrated in several cancer cell lines that this mutant causes apoptosis and confirmed these results in three xenograft breast cancer mice models. Interestingly, this survivin mutant was not able to cause apoptosis in proliferating normal human cells (Mesri et al. 2001).

\subsubsection{Ras}

The RAS supergene family is divided into six subfamilies RAS, RHO, RAB, ARF, RAN and RAD which code for more than 50 structurally related proteins. Their main function is to transmit signals from cell-surface receptors to the cell interior. All proteins have a guanosine triphosphate (GTP) binding motif in common and participate in signaling cascades. The RAS subfamily functions in proliferation and differentiation which makes it a prime target for anti-cancer therapy. The localization of Ras on the cell membrane, and binding to GTP are essential for its function. When Ras binds to GTP, it initiates the signaling pathway for cell proliferation and differentiation. However, when Ras-GTP is hydrolyzed to Ras-GDP by GTPase-activating proteins (GAPs), it is unable to activate its signal transduction pathway. This sensitive regulation process is out of balance in cancer cells due to different mutations in the RAS gene. Most of these mutations occur in the Ras gene itself and in the regulatory proteins of the Ras pathway. These mutations cause Ras to stay in the active Ras-GTP form and prevent conversion into the inactive Ras-GDP form. Mutated Ras protein is hyperactive and triggers cancer development. Hyperactive Ras is associated with different types of solid tumors such as pancreatic, cervical, thyroid, colon, skin, and lung tumors as well as with hematopoietic malignancies such as chronic myelomonocytic leukemia, acute myelogenous leukemia and multiple myeloma to list a few. Ras is an excellent gene therapy target due to its involvement in various cancers (Beaupre \& Kurzrock 1999, and references therein). Recently it has been shown that knocking out Ras with an anti-Ras mRNA plasmidmediated short-hairpin RNA in combination with clinical drug vincristine resulted in inhibition of the growth of human hepatoma HepG2 in vivo (Sun et al. 2009). This illustrates once again that the combination of gene therapy with standard chemotherapy is a promising approach for treatment of cancer.

\subsubsection{AKT}

$\mathrm{AKT}$, a serine/threonine kinase, plays an essential role in oncogenesis. The AKT family consists of three cellular homologues AKT1, AKT2 and AKT3. The encoded proteins have a similar structure consisting of an amino-terminal pleckstrin homology domain, a short ahelical linker and a carboxy-terminal kinase domain. Tissues have different expression levels of the three homologues AKT1, AKT2 and AKT3, which is why it is not surprising that the three different variants of AKT are overexpressed in different types of cancers. For example, AKT1 is overexpressed in gastric cancer and is associated with poor prognosis in breast and prostate cancer; AKT2 is overexpressed in ovarian and pancreatic cancer. AKT3 is overexpressed in estrogen receptor-deficient breast cancer and in androgen-insensitive prostate cancer which implies that AKT3 contributes to aggressive steroid hormoneinsensitive cancer. AKT acquires growth signal autonomy and inhibits apoptosis in cancer 
cells. It promotes cell survival through its phosphorylation of MDM2, which enhances nuclear accumulation of MDM2. MDM2 inhibits the transcriptional activity of p53 and promotes its degradation by the proteasome (Testa \& Bellacosa 2001). AKT gene therapy has been conducted with an aerosol delivery system consisting of nano-sized glucosylated polyethylenimine (GPEI). It has been shown that this aerosol is capable of delivering AKT wild-type and kinase deficient genes into the lung of mice (Tehrani et al. 2007). Dominant negative alleles of AKT directly injected into lung carcinoma cells have also been shown to block cell survival and proliferation (Li, Simpson, et al. 1998).

\subsection{Protein-protein interactions}

A protein dimer or oligomer is a macromolecular structure formed by two (dimer) or several (oligomer) proteins of either same origin (homo-oligomers) or different origins (hetero-oligomers). For several proteins the formation of oligomers or dimers is essential in order to form functional systems. Both Bcr-Abl and p53 proteins function in the homooligomeric form. On the other hand, hemoglobin forms hetero-oligomers consisting of two a and two $\beta$ subunits to form a functional structure. If one of these subunits is defective or missing, the protein cannot master its tasks leading to diseases such as the previously described $\beta$-thalassemia. Mutations in the oligomerization domain can lead to loss of function. Dimer or oligomer formation is governed by non-covalent interactions, including salt bridges, hydrogen bonds and hydrophobic interactions. A common structural motif for dimerization is a coiled coil consisting of usually two to five a-helices that wind around one another like strands of a rope, meshed together like "knobs-into-holes." They contain a characteristic seven-residue sequence repeat (Mason \& Arndt 2004; Crick 1952). Coiled coil motifs play an important role in the function of several different proteins ranging from transcription factors such as Jun and Fos which are responsible for cell growth and proliferation (Glover \& Harrison 1995) to the oncoprotein Bcr-Abl which leads to cancer (McWhirter et al. 1993). A subgroup of the coiled coil motif is represented by the "leucine zipper", an unusually long a-helix with protruding leucine residues in periodic repetition. The leucine residues from one peptide interact with leucine residues from a second peptide, forming a molecular zipper (Landschulz et al. 1988). Another important dimerization interface for proteins is the helix-loop-helix (HLH) motif. Characterized by two a-helices connected by a short loop, this structure is highly conserved in many diverse organisms. Proteins containing this structure are transcription factors that are only functional as homoor hetero-dimers (Murre et al. 1994, and references therein). Important HLH family members are myc proteins which play an essential role in cell proliferation, differentiation, cell growth, and apoptosis, but are also involved in development of numerous kinds of cancer (Vita \& Henriksson 2006). Finally, another interaction motif is the zinc finger motif, containing several subgroups such as $\mathrm{C} 2 \mathrm{H} 2$, Gag knuckle, treble clef, zinc ribbon, Zn2/Cys6, TAZ2 domain like, zinc binding loops and metallothionein (Krishna et al. 2003). The $\mathrm{C} 2 \mathrm{H} 2$ zinc finger represents the most prevalent motif and contains a zinc ion coordinated by cysteines and histidines (Wolfe et al. 2000). Although most $\mathrm{C} 2 \mathrm{H} 2$ fingers apparently contribute to protein-DNA or protein-RNA interactions, examples for proteinprotein interactions also exist. One example is Ikaros, a transcription factor participating in gene silencing and activation in hematopoietic cells. In this protein, dimerization is important for its activity and affinity to DNA (McCarty et al. 2003, and references therein). In addition, more complex oligomerization structures exist. For example, p53 forms a dimer with an antiparallel $\beta$-sheet and an antiparallel helix-helix interface. Two dimers associate as a parallel helix-helix to form a tetramer (Jeffrey et al. 1995). 
Gene therapy may be used to enhance or inhibit dimerization interfaces. Currently, small molecule drugs are unable to re-establish the ability of proteins to form dimers with the aim of restoring their natural function. In contrast, gene therapy can supply dimerizationcapable and functional proteins. On the other hand, if the formation of a dimer is unwanted, it is possible to disrupt the dimerization interface of a disease-causing protein by introducing proteins into the cell which compete for dimerization. Normal dimerization of the disease-causing protein is then blocked, hence stopping the disease.

\subsubsection{Homo-oligomerization for apoptotic activity}

The classic example of a protein that is only functional as a homo-oligomer is p53. The protein p53 is 393 amino acids long and contains a transactivation domain (amino acids 143) and a proline-rich domain (amino acids 61-94), a DNA-binding domain (amino acids 110-286), a tetramerization domain (amino acids 326-355) and a regulatory region (amino acids 363-393) (Chene 2001). As already mentioned, mutations of TP53, the gene encoding for $\mathrm{p} 53$, occur in a large proportion of human cancers. Some of these mutations may prevent the formation of tetramers, which lead to loss of p53 function (Vogelstein et al. 2000). Not only does the site-specific binding to DNA depend on oligomerization, but so do a number of post-translational modifications of p53 which are believed to be important regulators of p53 activity (Chene 2001, and references therein). Reintroducing tetramerization-capable p53 using gene therapy may allow treatment of cancers which are caused by mutations in this region of TP53. So far 49 mutations in the tetramerization domain of p53 have been described, even though not all mutations prevent dimerization or tetramerization. Most of these occurring mutants still form tetrameric structures like wild-type p53 but with reduced stability (Kamada et al. 2011).

Another example where protein oligomerization yields functionality occurs with DJ-1. This protein bears cytoprotective functions within cells and protects neurons from stressful stimulants. A L166P mutation in the DJ-1 gene may prevent its ability to homodimerize, and it has been speculated that this can lead to neurodegeneration in autosomal recessive early onset Parkinsonism (Gorner et al. 2007, and references therein). Re-introduction of dimerization-capable DJ-1 with gene therapy is therefore a possible treatment option.

\subsubsection{Disruption of disease-causing homo-oligomerization}

Like p53, Bcr-Abl is also a protein that functions as a homo-oligomer (dimer of dimers). However, $\mathrm{Bcr}-\mathrm{Abl}$ derives oncogenic function rather than tumor suppression from oligomerization. Bcr-Abl results from the fusion of the breakpoint cluster region (Bcr) gene on chromosome 22 and the Abelson leukemia oncogene (Abl) on chromosome 9. This results in an abnormal shortened chromosome called the Philadelphia chromosome. Bcr-Abl functions as an oncoprotein leading to increased cell proliferation and inhibition of apoptosis due to the constitutive activation of tyrosine kinase activity and causes $95 \%$ of all cases of chronic myeloid leukemia (CML) (Sawyers 1999, and references therein). The oligomerization of $\mathrm{Bcr}-\mathrm{Abl}$ is essential for the activation of the tyrosine kinase activity of Bcr-Abl (McWhirter et al. 1993). Destroying the ability of Bcr-Abl to form tetramers or using the dimerization domain to disrupt Bcr-Abl activity would be a possible gene therapy approach for CML (Dixon et al. 2009).

Finally, serpins (serine protease inhibitors) such as serpin a1-antitrypsin function aberrantly as oligomers/polymers (Silverman et al. 2001; Lomas \& Mahadeva 2002). In fact, the 
polymerization of serpin a1-antitrypsin is known to cause hepatocellular carcinoma and liver cirrhosis due to accumulation in the endoplasmatic reticulum of the liver (Lomas \& Mahadeva 2002). Disruption of polymerization could also be targeted for gene therapy, using an exogenously added polymerization domain that could compete for binding to serpin a1-antitrypsin.

\subsection{Cell compartments}

Targeting a gene therapy product to a specific subcellular compartment is another way to overcome disease. There are many diseases associated with protein malfunction in different organelles of the cell (Davis et al. 2007). For example, certain cancers can arise when a protein localizes to the wrong compartment. The typical example is cytoplasmically mislocalized p53. When p53 is in the cytoplasm, it cannot act as tumor suppressor since it is a transcription factor that needs to be in the nucleus in order to function (Kau et al. 2004; Wurzer et al. 2001). In addition to mislocation from the nucleus, the incorrect localization of proteins normally destined for lysosomes, peroxisomes, Golgi apparatus, endoplasmic reticulum (ER) or mitochondria can also lead to disease. Directing gene therapy products to specific subcellular compartments represents not only novel targets but a new way to approach gene therapy (Mossalam et al. 2010).

\subsubsection{Lysosomes}

Lysosomes degrade unused cellular constituents, receptors and release active enzymes extracellularly and are involved in post-translational maturation of proteins. Dysfunction of lysosomal hydrolases leads to loss of cell growth control and results in chemotherapy resistance as well as high metastatic potential (Castino et al. 2003). Furthermore, lysosome and lysosome-related organelles are associated with Lysosomal Storage Disease (LSD), Alzheimer's disease and development of several types of tumors. LSD is collective term for 40 genetic disorders due to single or multi enzyme deficiency which results in neurodegenerative disorders. Therapy options are limited to BMT and enzyme replacement. The disadvantages of BMT are morbidity and mortality as well as incomplete response to therapy. Enzyme replacement fails because of fast degradation of the enzyme from bloodstream. Due to these limitations, gene therapy represents a potential alternative. Currently, gene therapy is focused on using cargo proteins that deliver proteins to the lysosome. Since clathrin-dependent receptor-mediated endocytosis (RME) is the main transport mechanism for delivery to the lysosome, it is thought that all forms of LSDs can be treated with gene therapy (Bareford \& Swaan 2007, and references therein).

\subsubsection{Peroxisomes}

Peroxisomes are multifunctional organelles which are involved in biochemical and metabolic processes such as oxidation of fatty acids, plasmalogen biosynthesis and glyoxylate detoxification. Malfunction of or defects in peroxisomes are associated with a variety of diseases which can be classified as Zellweger spectrum peroxisome biogenesis disorders or rhizomelic chondrodysplasia punctate. Defects in peroxisome biogenesis proteins (peroxins, encoded by PEX genes) can lead to eye anomalies, extreme hypotension, and hepatomegaly (to name a few), and usually are fatal by age 1-2. In general deficiencies in a single peroxisomal enzyme (PEX) are associated with a variety of diseases. The therapy approaches are focused on protein therapeutics, peroxisomal enzymes and gene therapy. 
One possible gene therapy target is the antioxidant enzyme, catalase. A modified catalase molecule was transduced into hypocatalasemic fibroblasts and reduced hydrogen peroxide levels dramatically. This resulted in the restoration of oxidative balance, which may have cytoprotective effects (Terlecky \& Koepke 2007). The cytoprotective role of catalase makes it an excellent gene therapy target, because many diseases such as cardiovascular diseases are linked to high hydrogen peroxide levels (Gong et al. 2010).

\subsubsection{Proteasome}

Targeting the proteasome, the cell's degradation machinery, represents another possible target for gene therapy. The general inhibition of the proteasome is already used for treatment of inflammatory disease and cancer (Nalepa et al. 2006) while the activation of the proteasome can be used for neurodegenerative diseases and cardiac diseases (Dahlmann 2007). Targeting disease-specific components of the ubiquitin-proteasome system provides the possibility for directed therapy approaches (Nalepa et al. 2006). The E3 ubiqitin ligases are important for specificity of proteasomal degradation because they recognize the proteins which should be destroyed (Nalepa et al. 2006). More classical drug targets are the ubiquitin-activation and the actual degradation step which occurs in the proteasome. A new approach suggested by our lab involves capturing oncogenic proteins such as survivin and sending them to the proteasome for degradation. This could be achieved by including a gene therapy construct that has a survivin dimerization domain and a proteasomal degradation domain, capable of capturing endogenous survivin and sending it to the proteasome (Mossalam et al. 2010).

\subsubsection{Mitochondria}

Mitochondria are essential for production of cellular ATP. The mitochondria consist of the outer membrane, the inner membrane, intermembrane space, cristae and mitochondrial DNA. Mutations in mitochondrial DNA are associated with muscle and central nervous system dysfunction, but only if most of the DNA is mutated. An interesting gene therapy approach is to tag mitochondria targeting signals to endonucleases which are able to degrade the mutated mitochondrial DNA. This mutant DNA contains the T8399G mutation which creates a unique restriction site and allows the restriction enzyme to distinguish between normal DNA and mutated DNA. It provides new therapy options for neuropathy, ataxia and retinitis pigmentosa (Srivastava \& Moraes 2001). In addition, the mitochondrion is also essential in cellular apoptosis. Proteins such as p53 can be sent to the mitochondria, eventually resulting in cytochrome c release and apoptosis. Indeed, p53 targeted to the mitochondria has shown to cause apoptosis in different cancer cell lines (Palacios \& Moll 2006).

\subsubsection{Endoplasmic reticulum}

The endoplasmic reticulum (ER) produces almost all cellular lipids, and the majority of proteins are synthesized on the cytosolic surface of the ER. A wide range of diseases occur due to mistakes in protein folding/assembly in the ER such as CF and neurodegenerative diseases. CF is a classic gene therapy target with one single mutation which can be targeted by replacing the defect gene. Unfortunately, all gene therapy approaches for CF have failed thus far. Certain neurodegenerative diseases are affected by mutations in proteins involved in ER assembly. Mutations in Parkin, which is an E3 ligase responsible for ubiquitinylation 
and regulation of proteasomal degradation, is associated with juvenile Parkinsonism. The Parkin proteasomal pathway normally degrades Pael-R in dopaminergic neurons. Pael-R accumulates in brain cells when Parkin is mutated (Aridor et al. 2004, and references therein). Adding back functional Parkin would then be a possible gene therapy approach for juvenile Parkinsonism.

\subsubsection{Golgi apparatus}

In addition to the synthesis of carbohydrates, the Golgi apparatus (GA) sorts as well as dispatch proteins to the ER. SPCA1 is a protein found in the trans-Golgi. When mutations occur in the gene (ATP2C1) encoding SPCA1, a genetic disorder results called Hailey-Hailey disease. These various mutations result in skin lesions which are usually benign and lead only in a few cases into squamous cell carcinoma (Pizzo et al. 2011). Replacing mutated SPCA1 would be a possible gene therapy approach to treat Hailey-Hailey disease.

\subsubsection{Nucleus}

Many diseases are associated with problems in nuclear import and export. For example, various types of cancers are associated with p53 and FOXO mislocalization in the cytoplasm, while their normal localization is the nucleus. There are several examples of proteins that when mislocalized to different compartments lose their function or may become oncogenic. The control of compartmentalization of key proteins can be used to overcome disease. Besides, tumor suppressors such as p53, cell cycle inhibitors, G-protein coupled receptors and transcription factors can also lose their function when mislocalized (Chinen et al. 2007). p21WAF-1 is localized in the nucleus where it accomplishes its function as cell cycle inhibitor. When moved to the cytoplasm, it is associated with tumor progression (Davis et al. 2007; Keeshan et al. 2003). G-protein coupled receptors like rhodopsin, vasopressin $V_{2}$, LDL and CFTR all require proper localization for function. For example, rhodopsin is found in the membrane sacs within the rods, and when mislocalized it is confined in the plasma membrane of photoreceptor cell body and causes retinitis pigmentosa (Edwards et al. 2000). Additional transcription factors such as NF-kB and FOXO are both associated with various types of cancer when mislocalized to different compartments. NF- $\mathrm{kB}$ is located in the cytoplasm of normal cells whereas nuclear accumulation causes cancer. In contrast FOXO is found in the nucleus of normal cells and cytoplasmic localization results in cancer (Davis et al. 2007, and references therein).

There are several different gene therapy approaches for targeting mislocalized proteins. The standard method is to add back the protein which contains functional localization signals, such as the adenoviral p53 vectors Gendicine ${ }^{\mathrm{TM}}$ and Oncorine ${ }^{\mathrm{TM}}$. On the other hand, blocking general nuclear import or export machinery has been attempted, but due to the non-specific blockage of import/export, these methods suffer from toxicity. Instead of general inhibition of import/export, the protein itself can be modified. Adding nuclear localization signals (NLS) or nuclear export signals (NES) to the genes encoding mislocalized proteins allows targeting of proteins directly to the desired compartments.

The localization of proteins can be changed by using a protein switch developed in our laboratory (Kakar et al. 2007; Davis et al. 2007). The protein switch is a plasmid encoding a NES, a NLS and a ligand binding domain (LBD) from steroid hormone receptor. The LBD serves as a ligand-inducible nuclear localization switch. The protein switch is cytoplasm in the absence of ligand and translocates to the nucleus when ligand is added. The protein 
switch has also been designed to contain dimerization domain that allows capture of an endogenous protein of interest. Upon ligand addition, the protein switch-endogenous protein complex will then translocate to the nucleus. Removal of the endogenous protein from the cytoplasm can result in decrease cytoplasmic signaling or increased apoptotic signaling in the nucleus, with potential use in cancer therapy (Kakar et al. 2007).

\section{Conclusions}

Some of the major diseases currently targeted by gene therapy include cancer, cardiovascular disease, HIV, and monogenic diseases. Despite many decades of gene therapy research on these diseases, there currently are very few products that have made it to market. The search for new gene therapy targets and improved methods are therefore warranted. The integration of new and standard technologies (genome sequencing, microarrays, improved analysis, and linkage to molecular and biochemical assays) recently have yielded methods to uncover new drivers of cancer (Akavia et al. 2010). In 2008, the NIH started its Undiagnosed Diseases Program. These NIH investigators first try to diagnose an illness by first looking at known genetic markers, followed by standard molecular and biochemical assays. If no candidate genes are revealed, they then use state-ofthe-art genetic analyses that can sequence the entire exome (all exons in the human genome) of a patient and their family; high resolution microarrays can genotype the rest of the genome to "bring genomics to the clinic." After comparison to family data and a reference sequence (from the Human Genome Project), the gene causing a particular rare disease may be discovered (Maxmen 2011). Currently patients enrolled in this program are not cured; the candidate gene and corresponding protein are only identified. Small molecule inhibitors of these proteins can take years or decades to screen, therefore making replacement of these defective or mutant genes prime candidates for gene therapy treatment in patients with a rare disease.

Further analysis of the protein can uncover the molecular basis of the disease. Is this protein a hub protein which interacts with many other proteins? What are the protein-protein interactions that govern its activity? Are there any cell compartmentalization abnormalities that promote disease? With this information in mind, more modern gene therapy approaches can be developed. In our laboratory, we have designed a protein switch designed to capture and change location of a harmful protein in a cell. This altered location could be exploited for disease therapy. For example, the Bcr-Abl protein is oncogenic in the cytoplasm, but causes apoptosis when moved to the nucleus (Dixon et al. 2009). A protein switch against Bcr-Abl is being developed in our laboratory that can dimerize to wild type (wt) Bcr-Abl by virtue of a coiled-coil dimerization domain (Mossalam et al. 2010). The protein switch also contains a ligand-inducible domain that can move the protein from the cytoplasm to the nucleus upon the addition of ligand (Kakar et al. 2007). Therefore, after capture, wt Bcr-Abl is dragged to the nucleus, where apoptosis ensues. Understanding the molecular mechanisms that govern protein activity can therefore be used as the next phase in gene therapy, where altered protein location can completely change the function of a protein. Other emerging modern gene therapy-based approaches including anti-gene therapies (antisense, siRNA, ribozymes) and immunotherapy are desired to have a significant impact on disease treatment. 


\section{References}

Abo-Auda, W., and R. L. Benza. 2003. Therapeutic angiogenesis: review of current concepts and future directions. J Heart Lung Transplant 22 (4):370-82.

Akavia, U. D., O. Litvin, J. Kim, F. Sanchez-Garcia, D. Kotliar, H. C. Causton, P. Pochanard, E. Mozes, L. A. Garraway, and D. Pe'er. 2010. An integrated approach to uncover drivers of cancer. Cell 143 (6):1005-17.

Altieri, D. C. 2001. The molecular basis and potential role of survivin in cancer diagnosis and therapy. Trends Mol Med 7 (12):542-7.

Altieri, D. C. 2003. Validating survivin as a cancer therapeutic target. Nat Rev Cancer 3 (1):4654.

Altieri, D. C. 2008. Survivin, cancer networks and pathway-directed drug discovery. Nat Rev Cancer 8 (1):61-70.

Antoine, C., S. Muller, A. Cant, M. Cavazzana-Calvo, P. Veys, J. Vossen, A. Fasth, C. Heilmann, N. Wulffraat, R. Seger, S. Blanche, W. Friedrich, M. Abinun, G. Davies, R. Bredius, A. Schulz, P. Landais, and A. Fischer. 2003. Long-term survival and transplantation of haemopoietic stem cells for immunodeficiencies: report of the European experience 1968-99. Lancet 361 (9357):553-60.

Aridor, M., A. K. Guzik, A. Bielli, and K. N. Fish. 2004. Endoplasmic reticulum export site formation and function in dendrites. J Neurosci 24 (15):3770-6.

Arnett, D. K., A. E. Baird, R. A. Barkley, C. T. Basson, E. Boerwinkle, S. K. Ganesh, D. M. Herrington, Y. Hong, C. Jaquish, D. A. McDermott, and C. J. O'Donnell. 2007. Relevance of genetics and genomics for prevention and treatment of cardiovascular disease: a scientific statement from the American Heart Association Council on Epidemiology and Prevention, the Stroke Council, and the Functional Genomics and Translational Biology Interdisciplinary Working Group. Circulation 115 (22):2878-901.

Bareford, L. M., and P. W. Swaan. 2007. Endocytic mechanisms for targeted drug delivery. Adv Drug Deliv Rev 59 (8):748-58.

Baumgartner, I., N. Chronos, A. Comerota, T. Henry, J. P. Pasquet, F. Finiels, A. Caron, J. F. Dedieu, R. Pilsudski, and P. Delaere. 2009. Local gene transfer and expression following intramuscular administration of FGF-1 plasmid DNA in patients with critical limb ischemia. Mol Ther 17 (5):914-21.

Beaupre, D. M., and R. Kurzrock. 1999. RAS and leukemia: from basic mechanisms to genedirected therapy. J Clin Oncol 17 (3):1071-9.

Boucher, R. C., C. U. Cotton, J. T. Gatzy, M. R. Knowles, and J. R. Yankaskas. 1988. Evidence for reduced $\mathrm{Cl}-$ and increased $\mathrm{Na}+$ permeability in cystic fibrosis human primary cell cultures. J Physiol 405:77-103.

Buckley, R. H., R. I. Schiff, S. E. Schiff, M. L. Markert, L. W. Williams, T. O. Harville, J. L. Roberts, and J. M. Puck. 1997. Human severe combined immunodeficiency: genetic, phenotypic, and functional diversity in one hundred eight infants. J Pediatr 130 (3):378-87.

Cao, A., and R. Galanello. 2010. Beta-thalassemia. Genet Med 12 (2):61-76.

CardioVascular BioTherapeutics, Inc. 2011. Fibroblast Growth Factor-1 (FGF-1) for the Treatment of Coronary Heart Disease (ACORD) [cited 03/2011 2011]. Available from http://www.clinicaltrials.gov/ct2/show/NCT00117936?term=henry+FGF\&rank=1. 
Castino, R., M. Demoz, and C. Isidoro. 2003. Destination 'lysosome': a target organelle for tumour cell killing? J Mol Recognit 16 (5):337-48.

Cavazzana-Calvo, M., S. Hacein-Bey, G. de Saint Basile, F. Gross, E. Yvon, P. Nusbaum, F. Selz, C. Hue, S. Certain, J. L. Casanova, P. Bousso, F. L. Deist, and A. Fischer. 2000. Gene therapy of human severe combined immunodeficiency (SCID)-X1 disease. Science 288 (5466):669-72.

Cavazzana-Calvo, M., E. Payen, O. Negre, G. Wang, K. Hehir, F. Fusil, J. Down, M. Denaro, T. Brady, K. Westerman, R. Cavallesco, B. Gillet-Legrand, L. Caccavelli, R. Sgarra, L. Maouche-Chretien, F. Bernaudin, R. Girot, R. Dorazio, G. J. Mulder, A. Polack, A. Bank, J. Soulier, J. Larghero, N. Kabbara, B. Dalle, B. Gourmel, G. Socie, S. Chretien, N. Cartier, P. Aubourg, A. Fischer, K. Cornetta, F. Galacteros, Y. Beuzard, E. Gluckman, F. Bushman, S. Hacein-Bey-Abina, and P. Leboulch. 2010. Transfusion independence and HMGA2 activation after gene therapy of human beta-thalassaemia. Nature 467 (7313):318-22.

Cerepro, EMEA recommendation on. 2009. European Medicines Agency recommendation on Cerepro.

Chene, P. 2001. The role of tetramerization in p53 function. Oncogene 20 (21):2611-7.

Chinen, J., J. Davis, S. S. De Ravin, B. N. Hay, A. P. Hsu, G. F. Linton, N. Naumann, E. Y. Nomicos, C. Silvin, J. Ulrick, N. L. Whiting-Theobald, H. L. Malech, and J. M. Puck. 2007. Gene therapy improves immune function in preadolescents with X-linked severe combined immunodeficiency. Blood 110 (1):67-73.

Chiuve, S. E., M. L. McCullough, F. M. Sacks, and E. B. Rimm. 2006. Healthy lifestyle factors in the primary prevention of coronary heart disease among men: benefits among users and nonusers of lipid-lowering and antihypertensive medications. Circulation $114(2): 160-7$.

Cloutier, M. M., L. Guernsey, P. Mattes, and B. Koeppen. 1990. Duramycin enhances chloride secretion in airway epithelium. Am J Physiol 259 (3 Pt 1):C450-4.

Consortium, International HapMap. 2003. The International HapMap Project. Nature 426 (6968):789-96.

Crick, F. H. 1952. Is alpha-keratin a coiled coil? Nature 170 (4334):882-3.

Dahlmann, B. 2007. Role of proteasomes in disease. BMC Biochem 8 Suppl 1:S3.

Davis, J. R., M. Kakar, and C. S. Lim. 2007. Controlling protein compartmentalization to overcome disease. Pharm Res 24 (1):17-27.

De Ravin, S. S., and H. L. Malech. 2009. Partially corrected X-linked severe combined immunodeficiency: long-term problems and treatment options. Immunol Res 43 (13):223-42.

Dixon, A. S., M. Kakar, K. M. Schneider, J. E. Constance, B. C. Paullin, and C. S. Lim. 2009. Controlling subcellular localization to alter function: Sending oncogenic Bcr-Abl to the nucleus causes apoptosis. J Control Release 140 (3):245-9.

Duggan, D. J., M. Bittner, Y. Chen, P. Meltzer, and J. M. Trent. 1999. Expression profiling using cDNA microarrays. Nat Genet 21 (1 Suppl):10-4.

Edelstein, M. L., M. R. Abedi, and J. Wixon. 2007. Gene therapy clinical trials worldwide to 2007--an update. J Gene Med 9 (10):833-42.

Edelstein, M. L., M. R. Abedi, J. Wixon, and R. M. Edelstein. 2004. Gene therapy clinical trials worldwide 1989-2004-an overview. J Gene Med 6 (6):597-602. 
Edwards, S. W., C. M. Tan, and L. E. Limbird. 2000. Localization of G-protein-coupled receptors in health and disease. Trends Pharmacol Sci 21 (8):304-8.

Erster, S., M. Mihara, R. H. Kim, O. Petrenko, and U. M. Moll. 2004. In vivo mitochondrial p53 translocation triggers a rapid first wave of cell death in response to DNA damage that can precede p53 target gene activation. Mol Cell Biol 24 (15):6728-41.

Flume, P. A., P. J. Mogayzel Jr, K. A. Robinson, R. L. Rosenblatt, L. Quittell, B. C. Marshall, and Committee Clinical Practice Guidelines For Pulmonary Therapies. 2010. Cystic Fibrosis Pulmonary Guidelines: Pulmonary Complications: Hemoptysis and Pneumothorax. Am J Respir Crit Care Med.

Flynn, A., and T. O'Brien. 2008. Alferminogene tadenovec, an angiogenic FGF4 gene therapy for coronary artery disease. IDrugs 11 (4):283-93.

Foundation, Cystic Fibrosis. 2011. Cystic Fibrosis Foundation 2011 [cited 01/18/2011 2011]. Available from http://www.cff.org/.

Garber, K. 2006. China approves world's first oncolytic virus therapy for cancer treatment. J Natl Cancer Inst 98 (5):298-300.

Glover, J. N., and S. C. Harrison. 1995. Crystal structure of the heterodimeric bZIP transcription factor c-Fos-c-Jun bound to DNA. Nature 373 (6511):257-61.

Goh, A. M., C. R. Coffill, and D. P. Lane. 2010. The role of mutant p53 in human cancer. J Pathol.

Goh, A. M., C. R. Coffill, and D. P. Lane. 2011. The role of mutant p53 in human cancer. J Pathol 223 (2):116-26.

Gong, G., Y. Qin, W. Huang, S. Zhou, X. Wu, X. Yang, Y. Zhao, and D. Li. 2010. Protective effects of diosgenin in the hyperlipidemic rat model and in human vascular endothelial cells against hydrogen peroxide-induced apoptosis. Chem Biol Interact 184 (3):366-75.

Gorner, K., E. Holtorf, J. Waak, T. T. Pham, D. M. Vogt-Weisenhorn, W. Wurst, C. Haass, and P. J. Kahle. 2007. Structural determinants of the C-terminal helix-kink-helix motif essential for protein stability and survival promoting activity of DJ-1. J Biol Chem 282 (18):13680-91.

Grossman, D., and D. C. Altieri. 2001. Drug resistance in melanoma: mechanisms, apoptosis, and new potential therapeutic targets. Cancer Metastasis Rev 20 (1-2):3-11.

Guo, J., and H. Xin. 2006. Chinese gene therapy. Splicing out the West? Science 314 (5803):1232-5.

Guo, Z. S., S. H. Thorne, and D. L. Bartlett. 2008. Oncolytic virotherapy: molecular targets in tumor-selective replication and carrier cell-mediated delivery of oncolytic viruses. Biochim Biophys Acta 1785 (2):217-31.

Hacein-Bey-Abina, S., F. Le Deist, F. Carlier, C. Bouneaud, C. Hue, J. P. De Villartay, A. J. Thrasher, N. Wulffraat, R. Sorensen, S. Dupuis-Girod, A. Fischer, E. G. Davies, W. Kuis, L. Leiva, and M. Cavazzana-Calvo. 2002. Sustained correction of X-linked severe combined immunodeficiency by ex vivo gene therapy. N Engl J Med 346 (16):1185-93.

Harvey, B. G., P. L. Leopold, N. R. Hackett, T. M. Grasso, P. M. Williams, A. L. Tucker, R. J. Kaner, B. Ferris, I. Gonda, T. D. Sweeney, R. Ramalingam, I. Kovesdi, S. Shak, and R. G. Crystal. 1999. Airway epithelial CFTR mRNA expression in cystic fibrosis patients after repetitive administration of a recombinant adenovirus. J Clin Invest 104 (9):1245-55. 
Haupt, S., M. Berger, Z. Goldberg, and Y. Haupt. 2003. Apoptosis - the p53 network. J Cell Sci 116 (Pt 20):4077-85.

Henderson, B. R. 2005. Regulation of BRCA1, BRCA2 and BARD1 intracellular trafficking. Bioessays 27 (9):884-93.

Hirschhorn, J. N., and M. J. Daly. 2005. Genome-wide association studies for common diseases and complex traits. Nat Rev Genet 6 (2):95-108.

Jeffrey, P. D., S. Gorina, and N. P. Pavletich. 1995. Crystal structure of the tetramerization domain of the p53 tumor suppressor at 1.7 angstroms. Science 267 (5203):1498-502.

Kakar, M., J. R. Davis, S. E. Kern, and C. S. Lim. 2007. Optimizing the protein switch: altering nuclear import and export signals, and ligand binding domain. J Control Release 120 (3):220-32.

Kamada, R., T. Nomura, C. W. Anderson, and K. Sakaguchi. 2011. Cancer-associated p53 tetramerization domain mutants: quantitative analysis reveals a low threshold for tumor suppressor inactivation. J Biol Chem 286 (1):252-8.

Kass, R. W., M. N. Kotler, and S. Yazdanfar. 1992. Stimulation of coronary collateral growth: current developments in angiogenesis and future clinical applications. Am Heart J 123 (2):486-96.

Kato, J., Y. Kuwabara, M. Mitani, N. Shinoda, A. Sato, T. Toyama, A. Mitsui, T. Nishiwaki, S. Moriyama, J. Kudo, and Y. Fujii. 2001. Expression of survivin in esophageal cancer: correlation with the prognosis and response to chemotherapy. Int J Cancer 95 (2): 92-5.

Kau, T. R., J. C. Way, and P. A. Silver. 2004. Nuclear transport and cancer: from mechanism to intervention. Nat Rev Cancer 4 (2):106-17.

Keeshan, K., T. G. Cotter, and S. L. McKenna. 2003. Bcr-Abl upregulates cytosolic p21WAF1/CIP-1 by a phosphoinositide-3-kinase (PI3K)-independent pathway. $\mathrm{Br} J$ Haematol 123 (1):34-44.

Kerem, B., J. M. Rommens, J. A. Buchanan, D. Markiewicz, T. K. Cox, A. Chakravarti, M. Buchwald, and L. C. Tsui. 1989. Identification of the cystic fibrosis gene: genetic analysis. Science 245 (4922):1073-80.

Keskin, O., and R. Nussinov. 2007. Similar binding sites and different partners: implications to shared proteins in cellular pathways. Structure 15 (3):341-54.

Kim, P. M., L. J. Lu, Y. Xia, and M. B. Gerstein. 2006. Relating three-dimensional structures to protein networks provides evolutionary insights. Science 314 (5807):1938-41.

Kitchen, S. G., S. Shimizu, and D. S. An. 2011. Stem cell-based anti-HIV gene therapy. Virology 411 (2):260-72.

Knowlton, R. G., O. Cohen-Haguenauer, N. Van Cong, J. Frezal, V. A. Brown, D. Barker, J. C. Braman, J. W. Schumm, L. C. Tsui, M. Buchwald, and et al. 1985. A polymorphic DNA marker linked to cystic fibrosis is located on chromosome 7. Nature 318 (6044):380-2.

Kobayashi, N., K. Agematsu, K. Sugita, M. Sako, S. Nonoyama, A. Yachie, S. Kumaki, S. Tsuchiya, H. D. Ochs, Y. Fukushima, and A. Komiyama. 2003. Novel Artemis gene mutations of radiosensitive severe combined immunodeficiency in Japanese families. Hum Genet 112 (4):348-52.

Krishna, S. S., I. Majumdar, and N. V. Grishin. 2003. Structural classification of zinc fingers: survey and summary. Nucleic Acids Res 31 (2):532-50. 
Kung, C., J. T. Pingel, M. Heikinheimo, T. Klemola, K. Varkila, L. I. Yoo, K. Vuopala, M. Poyhonen, M. Uhari, M. Rogers, S. H. Speck, T. Chatila, and M. L. Thomas. 2000. Mutations in the tyrosine phosphatase CD45 gene in a child with severe combined immunodeficiency disease. Nat Med 6 (3):343-5.

Landschulz, W. H., P. F. Johnson, and S. L. McKnight. 1988. The leucine zipper: a hypothetical structure common to a new class of DNA binding proteins. Science 240 (4860):1759-64.

Li, F., G. Ambrosini, E. Y. Chu, J. Plescia, S. Tognin, P. C. Marchisio, and D. C. Altieri. 1998. Control of apoptosis and mitotic spindle checkpoint by survivin. Nature 396 (6711):580-4.

Li, J., L. Simpson, M. Takahashi, C. Miliaresis, M. P. Myers, N. Tonks, and R. Parsons. 1998. The PTEN/MMAC1 tumor suppressor induces cell death that is rescued by the AKT/protein kinase B oncogene. Cancer Res 58 (24):5667-72.

Li, J., and J. Yuan. 2008. Caspases in apoptosis and beyond. Oncogene 27 (48):6194-206.

Liu, R., W. A. Paxton, S. Choe, D. Ceradini, S. R. Martin, R. Horuk, M. E. MacDonald, H. Stuhlmann, R. A. Koup, and N. R. Landau. 1996. Homozygous defect in HIV-1 coreceptor accounts for resistance of some multiply-exposed individuals to HIV-1 infection. Cell 86 (3):367-77.

Lockley, M., M. Fernandez, Y. Wang, N. F. Li, S. Conroy, N. Lemoine, and I. McNeish. 2006. Activity of the adenoviral E1A deletion mutant d1922-947 in ovarian cancer: comparison with E1A wild-type viruses, bioluminescence monitoring, and intraperitoneal delivery in icodextrin. Cancer Res 66 (2):989-98.

Lomas, D. A., and R. Mahadeva. 2002. Alpha1-antitrypsin polymerization and the serpinopathies: pathobiology and prospects for therapy. J Clin Invest 110 (11):158590.

Lomas, David A., and Ravi Mahadeva. 2002. a1-Antitrypsin polymerization and the serpinopathies: pathobiology and prospects for therapy. The Journal of Clinical Investigation 110 (11):1585-1590.

Lucarelli, G., and J. Gaziev. 2008. Advances in the allogeneic transplantation for thalassemia. Blood Rev 22 (2):53-63.

Malik, P., and P. I. Arumugam. 2005. Gene Therapy for beta-thalassemia. Hematology Am Soc Hematol Educ Program:45-50.

Mason, J. M., and K. M. Arndt. 2004. Coiled coil domains: stability, specificity, and biological implications. Chembiochem 5 (2):170-6.

Maulik, N. 2009. NV1FGF, a pCOR plasmid-based angiogenic gene therapy for the treatment of intermittent claudication and critical limb ischemia. Curr Opin Investig Drugs 10 (3):259-68.

Maxmen, A. 2011. Exome sequencing deciphers rare diseases. Cell 144 (5):635-7.

McCarty, A. S., G. Kleiger, D. Eisenberg, and S. T. Smale. 2003. Selective dimerization of a C2H2 zinc finger subfamily. Mol Cell 11 (2):459-70.

McPhail, G. L., J. D. Acton, M. C. Fenchel, R. S. Amin, and M. Seid. 2008. Improvements in lung function outcomes in children with cystic fibrosis are associated with better nutrition, fewer chronic pseudomonas aeruginosa infections, and dornase alfa use. J Pediatr 153 (6):752-7. 
McWhirter, J. R., D. L. Galasso, and J. Y. Wang. 1993. A coiled-coil oligomerization domain of $\mathrm{Bcr}$ is essential for the transforming function of Bcr-Abl oncoproteins. Mol Cell Biol 13 (12):7587-95.

Mesri, M., N. R. Wall, J. Li, R. W. Kim, and D. C. Altieri. 2001. Cancer gene therapy using a survivin mutant adenovirus. J Clin Invest 108 (7):981-90.

Metcalfe, K. A., H. T. Lynch, P. Ghadirian, N. Tung, I. A. Olivotto, W. D. Foulkes, E. Warner, O. Olopade, A. Eisen, B. Weber, J. McLennan, P. Sun, and S. A. Narod. 2005. The risk of ovarian cancer after breast cancer in BRCA1 and BRCA2 carriers. Gynecol Oncol 96 (1):222-6.

Mitchell, P. 2010. Ark's gene therapy stumbles at the finish line. Nat Biotechnol 28 (3):183-4.

Morishita, R., M. Aoki, N. Hashiya, H. Makino, K. Yamasaki, J. Azuma, Y. Sawa, H. Matsuda, Y. Kaneda, and T. Ogihara. 2004. Safety evaluation of clinical gene therapy using hepatocyte growth factor to treat peripheral arterial disease. Hypertension 44 (2):203-9.

Moss, R. B., C. Milla, J. Colombo, F. Accurso, P. L. Zeitlin, J. P. Clancy, L. T. Spencer, J. Pilewski, D. A. Waltz, H. L. Dorkin, T. Ferkol, M. Pian, B. Ramsey, B. J. Carter, D. B. Martin, and A. E. Heald. 2007. Repeated aerosolized AAV-CFTR for treatment of cystic fibrosis: a randomized placebo-controlled phase 2B trial. Hum Gene Ther 18 (8):726-32.

Moss, R. B., D. Rodman, L. T. Spencer, M. L. Aitken, P. L. Zeitlin, D. Waltz, C. Milla, A. S. Brody, J. P. Clancy, B. Ramsey, N. Hamblett, and A. E. Heald. 2004. Repeated adeno-associated virus serotype 2 aerosol-mediated cystic fibrosis transmembrane regulator gene transfer to the lungs of patients with cystic fibrosis: a multicenter, double-blind, placebo-controlled trial. Chest 125 (2):509-21.

Mossalam, M., A. S. Dixon, and C. S. Lim. 2010. Controlling subcellular delivery to optimize therapeutic effect. Ther Deliv 1 (1):169-193.

Murre, C., G. Bain, M. A. van Dijk, I. Engel, B. A. Furnari, M. E. Massari, J. R. Matthews, M. W. Quong, R. R. Rivera, and M. H. Stuiver. 1994. Structure and function of helixloop-helix proteins. Biochim Biophys Acta 1218 (2):129-35.

Nakamura, Y. 2009. DNA variations in human and medical genetics: 25 years of my experience. J Hum Genet 54 (1):1-8.

Nalepa, G., M. Rolfe, and J. W. Harper. 2006. Drug discovery in the ubiquitin-proteasome system. Nat Rev Drug Discov 5 (7):596-613.

NCBI. 2011. Microarrays: Chipping away at the Mysteries of science and medicine 2007 [cited 03/2011 2011]. Available from http://www.ncbi.nlm.nih.gov/About/primer/microarrays.html.

O'Connor, D. S., D. Grossman, J. Plescia, F. Li, H. Zhang, A. Villa, S. Tognin, P. C. Marchisio, and D. C. Altieri. 2000. Regulation of apoptosis at cell division by p34cdc2 phosphorylation of survivin. Proc Natl Acad Sci U S A 97 (24):13103-7.

Palacios, G., and U. M. Moll. 2006. Mitochondrially targeted wild-type p53 suppresses growth of mutant p53 lymphomas in vivo. Oncogene 25 (45):6133-9.

Peng, Z. 2005. Current status of gendicine in China: recombinant human Ad-p53 agent for treatment of cancers. Hum Gene Ther 16 (9):1016-27.

Pizzo, P., V. Lissandron, P. Capitanio, and T. Pozzan. 2011. Ca(2+) signalling in the Golgi apparatus. Cell Calcium. 
Powell, R. J., M. Simons, F. O. Mendelsohn, G. Daniel, T. D. Henry, M. Koga, R. Morishita, and B. H. Annex. 2008. Results of a double-blind, placebo-controlled study to assess the safety of intramuscular injection of hepatocyte growth factor plasmid to improve limb perfusion in patients with critical limb ischemia. Circulation 118 (1):58-65.

Project, Human Genome. 2011. Human Genome Project 2011]. Available from http://www.ornl.gov/sci/techresources/Human_Genome/home.shtml.

Project, The International HapMap. 426. The International HapMap Project (2003/12/20), Dec 182003 [cited 6968 426]. Available from http://www.ncbi.nlm.nih.gov/pubmed/14685227.

Puel, A., S. F. Ziegler, R. H. Buckley, and W. J. Leonard. 1998. Defective IL7R expression in $\mathrm{T}(-) \mathrm{B}(+) \mathrm{NK}(+)$ severe combined immunodeficiency. Nat Genet 20 (4):394-7.

Raty, J. K., J. T. Pikkarainen, T. Wirth, and S. Yla-Herttuala. 2008. Gene therapy: the first approved gene-based medicines, molecular mechanisms and clinical indications. Curr Mol Pharmacol 1 (1):13-23.

Riferminogene pecaplasmide. 2010. Am J Cardiovasc Drugs 10 (5):343-6.

Rodriguez, J. A., S. Schuchner, W. W. Au, M. Fabbro, and B. R. Henderson. 2004. Nuclearcytoplasmic shuttling of BARD1 contributes to its proapoptotic activity and is regulated by dimerization with BRCA1. Oncogene 23 (10):1809-20.

Roth, J. A., D. Nguyen, D. D. Lawrence, B. L. Kemp, C. H. Carrasco, D. Z. Ferson, W. K. Hong, R. Komaki, J. J. Lee, J. C. Nesbitt, K. M. Pisters, J. B. Putnam, R. Schea, D. M. Shin, G. L. Walsh, M. M. Dolormente, C. I. Han, F. D. Martin, N. Yen, K. Xu, L. C. Stephens, T. J. McDonnell, T. Mukhopadhyay, and D. Cai. 1996. Retrovirusmediated wild-type p53 gene transfer to tumors of patients with lung cancer. Nat Med 2 (9):985-91.

Ryan, B. M., N. O'Donovan, and M. J. Duffy. 2009. Survivin: a new target for anti-cancer therapy. Cancer Treat Rev 35 (7):553-62.

Ryser, O., A. Morell, and W. H. Hitzig. 1988. Primary immunodeficiencies in Switzerland: first report of the national registry in adults and children. J Clin Immunol 8 (6):47985.

Sawyers, C. L. 1999. Chronic myeloid leukemia. N Engl J Med 340 (17):1330-40.

Schwarz, K., G. H. Gauss, L. Ludwig, U. Pannicke, Z. Li, D. Lindner, W. Friedrich, R. A. Seger, T. E. Hansen-Hagge, S. Desiderio, M. R. Lieber, and C. R. Bartram. 1996. RAG mutations in human B cell-negative SCID. Science 274 (5284):97-9.

Shi, J., and D. Zheng. 2009. An update on gene therapy in China. Curr Opin Mol Ther 11 (5):547-53.

Shigematsu, H., K. Yasuda, T. Iwai, T. Sasajima, S. Ishimaru, Y. Ohashi, T. Yamaguchi, T. Ogihara, and R. Morishita. 2010. Randomized, double-blind, placebo-controlled clinical trial of hepatocyte growth factor plasmid for critical limb ischemia. Gene Ther 17 (9):1152-61.

Shiraishi, K., S. Kato, S. Y. Han, W. Liu, K. Otsuka, M. Sakayori, T. Ishida, M. Takeda, R. Kanamaru, N. Ohuchi, and C. Ishioka. 2004. Isolation of temperature-sensitive p53 mutations from a comprehensive missense mutation library. J Biol Chem 279 (1):34855. 
Siegmund, K. H., U. E. Steiner, and C. Richert. 2003. ChipCheck--a program predicting total hybridization equilibria for DNA binding to small oligonucleotide microarrays. $J$ Chem Inf Comput Sci 43 (6):2153-62.

Silverman, G. A., P. I. Bird, R. W. Carrell, F. C. Church, P. B. Coughlin, P. G. Gettins, J. A. Irving, D. A. Lomas, C. J. Luke, R. W. Moyer, P. A. Pemberton, E. RemoldO'Donnell, G. S. Salvesen, J. Travis, and J. C. Whisstock. 2001. The serpins are an expanding superfamily of structurally similar but functionally diverse proteins. Evolution, mechanism of inhibition, novel functions, and a revised nomenclature. $J$ Biol Chem 276 (36):33293-6.

Srivastava, S., and C. T. Moraes. 2001. Manipulating mitochondrial DNA heteroplasmy by a mitochondrially targeted restriction endonuclease. Hum Mol Genet 10 (26):3093-9.

Sun, H. X., H. W. He, S. H. Zhang, T. G. Liu, K. H. Ren, Q. Y. He, and R. G. Shao. 2009. Suppression of N-Ras by shRNA-expressing plasmid increases sensitivity of HepG2 cells to vincristine-induced growth inhibition. Cancer Gene Ther 16 (9):693702.

Symonds, G. P., H. A. Johnstone, M. L. Millington, M. P. Boyd, B. P. Burke, and L. R. Breton. 2010. The use of cell-delivered gene therapy for the treatment of HIV/AIDS. Immunol Res 48 (1-3):84-98.

Taha, T. A., W. Osta, L. Kozhaya, J. Bielawski, K. R. Johnson, W. E. Gillanders, G. S. Dbaibo, Y. A. Hannun, and L. M. Obeid. 2004. Down-regulation of sphingosine kinase-1 by DNA damage: dependence on proteases and p53. J Biol Chem 279 (19):20546-54.

Tehrani, A. M., S. K. Hwang, T. H. Kim, C. S. Cho, J. Hua, W. S. Nah, J. T. Kwon, J. S. Kim, S. H. Chang, K. N. Yu, S. J. Park, D. R. Bhandari, K. H. Lee, G. H. An, G. R. Beck, Jr., and M. H. Cho. 2007. Aerosol delivery of Akt controls protein translation in the lungs of dual luciferase reporter mice. Gene Ther 14 (5):451-8.

Tembe, V., and B. R. Henderson. 2007. BARD1 translocation to mitochondria correlates with Bax oligomerization, loss of mitochondrial membrane potential, and apoptosis. $J$ Biol Chem 282 (28):20513-22.

Terlecky, S. R., and J. I. Koepke. 2007. Drug delivery to peroxisomes: employing unique trafficking mechanisms to target protein therapeutics. Adv Drug Deliv Rev 59 (8):739-47.

Testa, J. R., and A. Bellacosa. 2001. AKT plays a central role in tumorigenesis. Proc Natl Acad Sci U S A 98 (20):10983-5.

Thrasher, A. J., S. Hacein-Bey-Abina, H. B. Gaspar, S. Blanche, E. G. Davies, K. Parsley, K. Gilmour, D. King, S. Howe, J. Sinclair, C. Hue, F. Carlier, C. von Kalle, G. de Saint Basile, F. le Deist, A. Fischer, and M. Cavazzana-Calvo. 2005. Failure of SCID-X1 gene therapy in older patients. Blood 105 (11):4255-7.

van Putten, E. H., C. M. Dirven, M. J. van den Bent, and M. L. Lamfers. 2010. Sitimagene ceradenovec: a gene-based drug for the treatment of operable high-grade glioma. Future Oncol 6 (11):1691-710.

Vaseva, A. V., N. D. Marchenko, and U. M. Moll. 2009. The transcription-independent mitochondrial p53 program is a major contributor to nutlin-induced apoptosis in tumor cells. Cell Cycle 8 (11):1711-9.

Ventura, A., D. G. Kirsch, M. E. McLaughlin, D. A. Tuveson, J. Grimm, L. Lintault, J. Newman, E. E. Reczek, R. Weissleder, and T. Jacks. 2007. Restoration of p53 function leads to tumour regression in vivo. Nature 445 (7128):661-5. 
Vita, M., and M. Henriksson. 2006. The Myc oncoprotein as a therapeutic target for human cancer. Semin Cancer Biol 16 (4):318-30.

Vogelstein, B., D. Lane, and A. J. Levine. 2000. Surfing the p53 network. Nature 408 (6810):307-10.

Weatherall, D. J. 1976. Molecular pathology of the thalassemia disorders. West J Med 124 (5):388-402.

WHO. 2011. Cancer 20112011]. Available from http://www.who.int/mediacentre/factsheets/fs297/en/.

Wolfe, S. A., L. Nekludova, and C. O. Pabo. 2000. DNA recognition by Cys2His2 zinc finger proteins. Annu Rev Biophys Biomol Struct 29:183-212.

Wood, B. P. 1997. Cystic fibrosis: 1997. Radiology 204 (1):1-10.

Wurzer, G., W. Mosgoeller, M. Chabicovsky, C. Cerni, and J. Wesierska-Gadek. 2001. Nuclear Ras: unexpected subcellular distribution of oncogenic forms. J Cell Biochem Suppl Suppl 36:1-11.

Xin, H. 2006. Chinese gene therapy. Gendicine's efficacy: hard to translate. Science 314 (5803):1233.

Xue, W., L. Zender, C. Miething, R. A. Dickins, E. Hernando, V. Krizhanovsky, C. CordonCardo, and S. W. Lowe. 2007. Senescence and tumour clearance is triggered by p53 restoration in murine liver carcinomas. Nature 445 (7128):656-60.

$\mathrm{Yu}$, W., and H. Fang. 2007. Clinical trials with oncolytic adenovirus in China. Curr Cancer Drug Targets 7 (2):141-8.

Zhao, J., T. Tenev, L. M. Martins, J. Downward, and N. R. Lemoine. 2000. The ubiquitinproteasome pathway regulates survivin degradation in a cell cycle-dependent manner. J Cell Sci 113 Pt 23:4363-71 


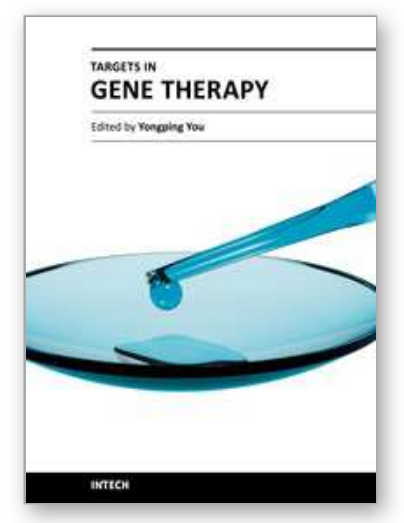

\author{
Targets in Gene Therapy \\ Edited by Prof. Yongping You
}

ISBN 978-953-307-540-2

Hard cover, 436 pages

Publisher InTech

Published online 23, August, 2011

Published in print edition August, 2011

This book aims at providing an up-to-date report to cover key aspects of existing problems in the emerging field of targets in gene therapy. With the contributions in various disciplines of gene therapy, the book brings together major approaches: Target Strategy in Gene Therapy, Gene Therapy of Cancer and Gene Therapy of Other Diseases. This source enables clinicians and researchers to select and effectively utilize new translational approaches in gene therapy and analyze the developments in target strategy in gene therapy.

\title{
How to reference
}

In order to correctly reference this scholarly work, feel free to copy and paste the following:

Karina J. Matissek, Ruben R. Bender, James R. Davis and Carol S. Lim (2011). Choosing Targets for Gene Therapy, Targets in Gene Therapy, Prof. Yongping You (Ed.), ISBN: 978-953-307-540-2, InTech, Available from: http://www.intechopen.com/books/targets-in-gene-therapy/choosing-targets-for-gene-therapy

\section{INTECH}

open science | open minds

\author{
InTech Europe \\ University Campus STeP Ri \\ Slavka Krautzeka 83/A \\ 51000 Rijeka, Croatia \\ Phone: +385 (51) 770447 \\ Fax: +385 (51) 686166 \\ www.intechopen.com
}

\author{
InTech China \\ Unit 405, Office Block, Hotel Equatorial Shanghai \\ No.65, Yan An Road (West), Shanghai, 200040, China \\ 中国上海市延安西路65号上海国际贵都大饭店办公楼405单元 \\ Phone: +86-21-62489820 \\ Fax: +86-21-62489821
}


(C) 2011 The Author(s). Licensee IntechOpen. This chapter is distributed under the terms of the Creative Commons Attribution-NonCommercialShareAlike-3.0 License, which permits use, distribution and reproduction for non-commercial purposes, provided the original is properly cited and derivative works building on this content are distributed under the same license. 